\title{
Who Opposes Immigrants' Integration into the Labor Market? The Swiss Case ${ }^{a}$
}

\author{
Tobias MÜller ${ }^{\mathrm{b}}$ and Silvio H. T. TaI ${ }^{\mathrm{c}}$
}

JEL-Classification: F22, J61, D72

Keywords: immigration, immigrant integration, guest-workers, political economy

\section{Introduction}

In several European countries, the integration of immigrants into the host country's economy and society ranks high on the political agenda. The debate is particularly heated in countries that had implemented guest-worker policies in the past since they have to deal today with the presence of large numbers of unskilled immigrants. From the perspective of these host countries, the wage assimilation of immigrants has been far from perfect (e.g. Dustmann, 1993) and immigrants are sometimes blamed for not making enough effort to participate in the labor market. ${ }^{1}$ From the perspective of immigrants, there is the perception that they do not have equal access to well-paid jobs in the host country. Such hiring discrimination has indeed been documented by field studies in Germany (GolDberg, Mourinho and Kulke, 1996; Kaas and Manger, 2010) and Switzerland (Fibbi, Lerch and Wanner, 2006).

However, when it comes to concrete proposals to improve the integration of low-skill migrants, there has been and still is popular resistance. The recent historical experience of Switzerland provides some examples. In 1964 the Swiss government signed a revised bilateral recruitment agreement with Italy, giving Italian seasonal workers the right to obtain an annual work permit and to change

a The authors would like to thank Jaime de Melo and Florence Miguet for stimulating comments. Financial support by the TOM ("Transnationality of Migrants") Marie-Curie Research and Training Network is gratefully acknowledged.

b Department of Econometrics, University of Geneva

c Department of Economics, University Paris Sud-XI

1 See for example the recent debate in Germany surrounding the controversial book on immigration written by a former member of the Executive Board of the Deutsche Bundesbank, Thilo Sarrazin. 
jobs after five consecutive years (seasons) worked in Switzerland. The publication of this accord caused "uproar in Swiss public opinion" (MAYER, 1965, p. 9) and its ratification was postponed because of a "storm of protests". In 1981 the Swiss electorate rejected massively the popular initiative "Être solidaires" which proposed to abolish the seasonal worker status and to put former seasonal workers on an equal footing with annual foreign workers. More recently, substantial opposition arose also against the free movement of persons which is part of the bilateral agreements between Switzerland and the European Union. ${ }^{2}$

Starting from these observations, our paper analyzes the attitudes of natives towards the integration of immigrants in the labor market. In particular, we address the question why natives often oppose measures that would give low-skill immigrants a better access to well-paid jobs in the host country. We formulate a political-economy model that explains why guest-worker policies are adopted in the first place (and preferred to a non-discriminatory immigration regime) and why measures to improve the integration of low-skill immigrants tend to be opposed subsequently. ${ }^{3}$ The main mechanism that explains these results is the existence of a dual labor market in the low-skill labor market, where "good" jobs are rationed because of efficiency-wage considerations. ${ }^{4}$ In a guest-worker system, most immigrants hold low-wage jobs because of the legal constraints to hiring and the high probabilities of immigrants' return that characterize such a migration regime. As a consequence, low-skill natives have higher chances of finding well-paid jobs than in a non-discriminatory immigration system. By the same token, low-skill native workers tend to oppose integration measures because these would increase competition for "good" jobs by enhancing the immigrants' chances of being hired for these types of jobs.

In our model, discrimination against immigrants is of the type "equal pay for equal work, but unequal work". The literature provides some evidence for such

2 The agreement on the free movement of persons (and its extension to the new EU member countries) includes both changes in immigration policy and an improvement of the EU migrants' status in the Swiss labor market. It should therefore not be interpreted as a "pure" integration policy measure. Moreover, this agreement is linked to the other bilateral agreements through the "guillotine clause".

3 The model is an extension of Müller (2003a) and is inspired by De Melo, Miguet and MÜLleR (2002).

4 Note that in their initial formulation of the shirking version of the efficiency-wage model, Shapiro and Stiglitz (1984) had the "lower-paid, lower-skilled, blue-collar occupations" (p. 443) in mind.

5 In a comparative framework, Bauer, Lofstrom and Zimmermann (2000) find that natives are more favorable to immigration if foreigners are selected according to the needs of the labor market. 
earnings patterns in Germany and Switzerland, two traditional "guest-worker" countries. Constant and Massey (2005) report that guest-workers initially find jobs with a much lower occupational status than comparably skilled natives in Germany. Dustmann's (1993) result that the immigrants' earnings do not catch up with natives' confirms this view. In a study focusing on segregation at the firm level, Müller and Ramirez (2008) find that firms with a large proportion of foreign unskilled workers pay low wages to all their employees and that segregation at the firm level accounts for almost the entire wage differential between identically skilled Swiss and foreign workers.

The empirical part of this paper is closely related to the recent literature that studies the determinants of natives' attitudes towards immigration. The first contributions in this branch of the literature consider labor market competition as the main determinant of attitudes (Scheve and Slaughter, 2001; Mayda, 2006; O'Rourke and Sinnott, 2006). More recent papers also take the welfare-state channel into account (FACCHINI and Mayda, 2009; and Hanson et al., 2007). Other authors demonstrate the importance of non-economic channels and include individual cultural values in their analysis (Dustman and Preston, 2007; Hainmueller and Hiscox, 2007; Müller and TAI, 2009).

Our empirical analysis focuses on attitudes towards the immigrants' integration, using data from the Vox surveys in Switzerland over the period 1993 to 2008. Our approach is inspired by the literature on attitudes towards immigration, although the questions are different. In particular, we follow ScHeve and SLAUghter's (2001) suggestion to assess the effect of education on attitudes separately for those who are inside or outside the labor force. If the effect is greater for the former group, it can be assumed to capture labor-market skills. We examine also Hainmueller and Hiscox's (2007) conjecture that university or college education leads to more tolerant attitudes towards other cultures. The particular nature of the dual education system in Switzerland enables us to shed new light on this issue: it is the academic nature of education that seems to be associated with more tolerant attitudes.

In the following section, we outline the political-economy model (a detailed description of the model is given in the appendix). Section 3 contains the empirical analysis of attitudes towards immigrants' integration in Switzerland and Section 4 concludes. 


\section{The Political Economy of Migrants' Integration}

If attitudes towards the integration of immigrants are to be explained in a meaningful way, the underlying model should account for the fact that immigration policies of the "guest-worker" type were implemented in the first place (as was the case in many European countries, see Castles, 1986). The model that we spell out below reflects the fact that guest-worker policies aimed at channeling immigrants into low-wage occupations or sectors, enhancing the natives' chances to find high-wage jobs. The sectoral segregation between natives and migrants is either the direct result of legal regulations (e.g. by issuing work permits with limited rights during a transition period) or the indirect outcome of differing economic incentives. Both cases are taken into account by our model.

\subsection{The Model}

We consider a setting with two alternatives up for vote when analyzing the political economy of immigration (no immigration vs. admission of a fixed number of immigrants) or the political economy of migrants' integration (no specific integration measures vs. improved integration of immigrants). An individual's attitude toward a specific immigration policy measure depends on the latter's effect on his expected income. If the policy measure lowers his expected income, he will oppose it. The national stance towards immigration or towards integration is determined by the median voter.

Natives are heterogeneous with respect to their level of education whereas immigrants are all unskilled. Natives do not know in advance whether they will get a skilled job or whether they will enter the unskilled labor market. The probability of obtaining a skilled job increases with the individual's level of education (this probability is zero for immigrants). ${ }^{6}$ Those who obtain unskilled jobs start by working in a low-wage job in the secondary sector, which is characterized by its unattractive jobs; their subsequent working career is described by the dual labor market model, with transitions between low-wage jobs (in the secondary sector) and well-paid jobs (in the primary sector).

The dual labor market is modeled in a standard efficiency-wage framework following Shapiro and Stiglitz (1984) and Bulow and Summers (1986), embedded in a small-country specific-factors model with prices normalized to 1 .

6 Those who obtain skilled jobs are allocated randomly to one of the two sectors. We assume that skilled workers are not able to switch sectors subsequently; their skills become specific to the sector where they are first hired. 
The economy produces two traded goods, $X$ and $Y$, using three types of labor: unskilled labor which is mobile between the two sectors, and skilled labor which is sector-specific $\left(H_{X}, H_{Y}\right)$. The skilled labor market is competitive and workers are paid their marginal product. In sector $Y$, firms offer good working conditions and pay above market-clearing wages to induce unskilled workers to supply effort. This sector will be labeled "primary sector", following the tradition in the labor economics literature. By contrast, $X$ is the "secondary sector" where unattractive and repetitive jobs can be monitored at no cost. As a consequence, unskilled jobs are rationed in the primary sector and workers are queuing up for them. However, they can always find unskilled jobs in the secondary sector where the wage rate is set competitively. There is no unemployment. ${ }^{7}$

Workers are assumed to maximize expected utility over their infinite life horizon, using discount rate $r$. Expected life-time utility of individual $i$ can be written as

$$
U_{i}^{e}=h_{i} U_{H}+\left(1-h_{i}\right) U_{X},
$$

where $h_{i}$ denotes the probability that the individual will be able to obtain a skilled job. This probability can be interpreted as a measure of the individual's level of education or human capital (suitably normalized). The average probability of obtaining a skilled job (or average education level) is $\bar{h}=H /(H+N)$, where $H$ is total skilled employment and $N$ total unskilled employment by natives. If the individual does not succeed in obtaining a skilled job, he enters the low-skill segment of the labor market and accepts a secondary-sector job (which is immediately available). Note that the expected life-time utility of such a job, $U_{X}$, takes into account the probability of finding a primary-sector job (see the appendix for details).

We assume for simplicity that an individual who obtains a skilled job will keep it forever. Expected life-time utility of a skilled job, $U_{H}$, is a weighted average of the life-time income that can be obtained in the two sectors, since the two type of jobs are allocated randomly between individuals who get access to skilled jobs:

$$
r U_{H}=\pi_{X} v\left(w_{H}^{X}, e\right)+\left(1-\pi_{X}\right) v\left(w_{H}^{Y}, e\right), \pi_{X}=\frac{H_{X}}{H_{X}+H_{Y}},
$$

7 For the effects of immigration in efficiency-wage models with unemployment, see MüLLER (2003b). 
where $\pi_{X}$ is the probability of working in sector $X$ (conditional on the fact that the individual has obtained a skilled job), $H_{X}$ and $H_{Y}$ denote native high-skill employment in sectors $X$ and $Y, w_{H}^{X}$ and $w_{H}^{Y}$ denote skilled wages in these two sectors. Finally, $v(w, e)=w-e$ is the instantaneous (indirect) utility function, where $e$ denotes the utility cost of effort. ${ }^{8}$

Consider now unskilled jobs where workers have the possibility to shirk (i.e., not to provide the required effort). The instantaneous utility function is given by $v(w, \varepsilon)=w-\varepsilon$, where the effort level $\varepsilon$ can take two values: 0 if the worker "shirks" and $e>0$ if he does not shirk. Assuming a steady-state equilibrium, the following no-shirking constraint (NSC) for natives in unskilled jobs is obtained:"

$$
w_{L}^{Y}-w_{L}^{X}=\frac{e}{b}\left(r+\frac{q N}{N-N_{Y}}\right)
$$

where $b$ is the probability of being discovered shirking (and, consequently, being fired), $q$ is the probability of a primary-sector job to end, $N_{Y}$ is native low-skill employment in the primary sector and $N$ is total native low-skill employment.

At equilibrium, the low-skill wage rate is equal to the marginal product of low-skill labor in each sector. The equilibrium in the low-skill labor market for natives is depicted in Figure 1, where $f^{X}\left(f^{Y}\right)$ denotes the constant-returns-to-scale production function of sector $X(Y)$. The upward-sloping curve is the natives' no-shirking condition (3), and the downward-sloping curve represents the difference between marginal products of labor in the two sectors. The intersection determines the equilibrium wage differential and native low-skill employment in both sectors (the employment of immigrants is considered exogenous in this figure). Note that, the equilibrium in the dual labor-market is inefficient. The distortion could be corrected by subsidizing primary-sector (high-income) employment. Since such a measure would meet with strong political opposition because of its anti-egalitarian implications, we assume that it is not realized.

The economic consequences of immigration obviously depend on the migrants' incentives and on migration policy. Indeed, a distinctive characteristic of immigrants is their probability of return, $\theta .^{10}$ Therefore, even if migrants are identical

8 For the sake of simplicity, we assume that workers do not have the possibility to choose the effort level in skilled jobs.

9 See the Appendix for the derivation of the no-shirking constraint.

10 In OECD (2008), estimates of average re-emigration rates after five years range from $60 \%$ (Ireland), 50\% (Belgium), and 40\% (United Kingdom, Norway) to 19\% (United States). 
Figure 1: Equilibrium in the Dual Labor Market

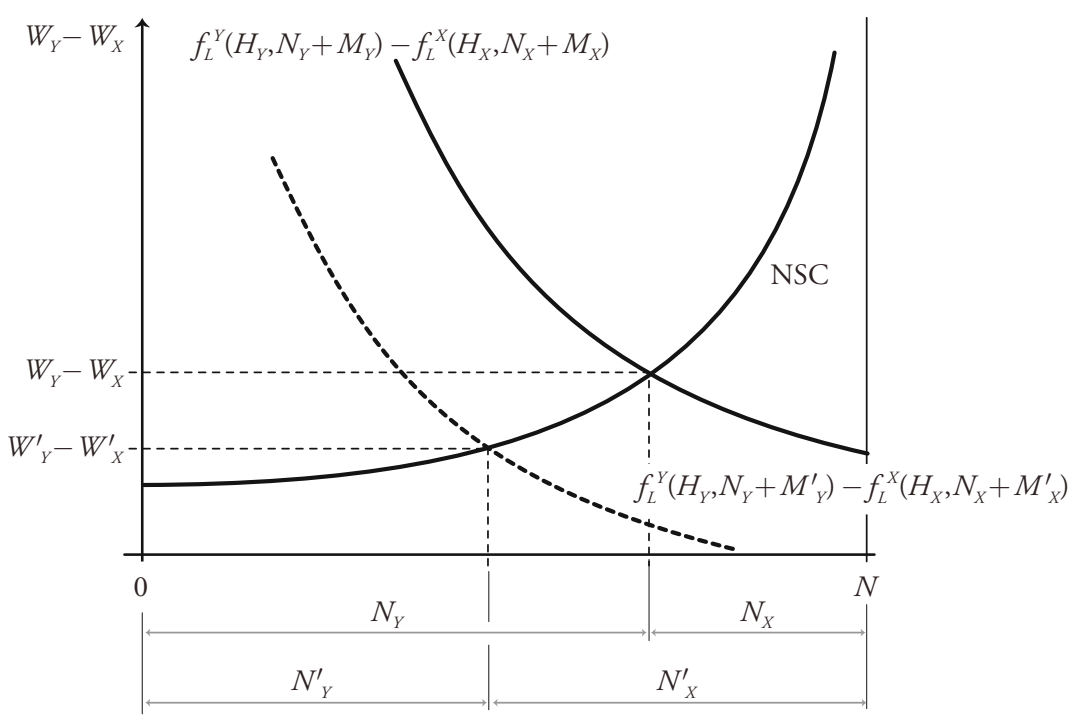

to low-skill natives in all other respects, their incentive not to shirk is influenced by the probability of return to their home country. ${ }^{11}$ Moreover, the return probability is influenced by various aspects of migration policy, such as the existence of temporary work permits, or the government's attitude towards social and economic integration of immigrants. Other legal dimensions of migration policy are equally important. In most countries, migrants are granted equal rights in the host country's labor market only after a certain period of stay, T. Firms are compelled to prefer natives and "old" migrants over "new" migrants in their hiring decision.

All these factors contribute to segregation and thus discrimination against migrants. Since competition ensures that natives and migrants are paid the same wages in low-skill jobs, discrimination is of the type "equal pay for equal work, but not equal work". Hence migrants have smaller chances of finding "good" jobs than low-skill natives and suffer from sectoral segregation. The extent of segregation which results from these differences in incentives can be summarized by

11 We assume that "old" immigrants, who are leaving the country, are replaced by new immigrants (steady-state assumption). 
the following equation (which is derived in the appendix) relating the migrants' chances of being employed in the primary sector $\left(M_{Y} / M\right)$ to that of the lowskill natives $\left(N_{Y} / N\right)$ :

$$
\frac{M_{Y}}{M}=e^{-\theta T}\left[\left(1+\frac{\theta}{q}\right) \frac{N_{Y}}{N}-\frac{\theta}{q}\right],
$$

where $M_{Y}$ is immigrant employment in the primary sector and $M$ denotes the total number of (low-skill) immigrants. With segregation, immigration increases the natives' chances of finding a job in the primary-sector by shifting the downward-sloping marginal-productivity schedule in Figure 1 to the right, since the NSC is not affected by migration.

\subsection{Guest-Worker Policies and Immigration}

Before we turn to the problem of migrants' integration into the host country, we use the model to analyze the choice of immigration policies. Does a "guestworker" system make a country more receptive for immigrants than a less discriminatory policy? To address this question, we consider two polar cases: first, an extreme "guest-worker" policy where legal constraints prevent immigrants from entering the primary sector, second, a non-discriminatory policy where immigrants have the same rights and incentives as natives. According to the model, additional immigration is more likely to be accepted by the electorate under a "guest-worker" system, a result which provides a rationale for past immigration policies in Switzerland.

Because of the distortion created by the dual labor market, the impact of an increase in immigration (or a change in integration policy) on the welfare of natives depends essentially on the policy measure's effect on native (low-skill) employment in the primary sector. If immigration increases the natives' chances of finding "good" low-skill jobs, the expected life-time utility of natives increases because the shift from "bad" to "good" jobs has a first-order effect on welfare. Formally, this is reflected by the following result: ${ }^{12}$

$$
d U_{X}=d U_{Y}=\frac{1}{r} d w_{L}^{Y}=\frac{1}{r} f_{L L}^{Y} d L_{Y} .
$$

12 This result is obtained by differentiating equations (A1) and (A3) in the appendix. 
Consider first the case of an extreme "guest-worker" policy $(\theta>0, T=\infty)$ resulting in complete segregation. It is shown in the appendix that all natives whose education level $h_{i}$ is greater than the following critical level will vote in favor of immigration: ${ }^{13}$

$$
h_{c}=\frac{H}{H+L_{Y}+L_{X}\left(1+\sigma_{Y} / \eta_{Y} s_{H}^{Y}\right)},
$$

where $\sigma_{Y}$ is the elasticity of substitution between skilled and unskilled labor in the primary sector, $s_{H}^{Y}$ is the share of skilled labor in the primary sector's labor costs, $\eta_{Y}$ is the elasticity of primary-sector employment with respect to wage along the NSC and $H=H_{X}+H_{Y}$. Thus the "guest-worker" system implies a critical level of education which is lower than the average education level since $h_{c}<H /(H+L)$. If the distribution of education levels is symmetric (or if the median education level is not too far below the average), the median voter will be in favor of immigration.

By contrast, with an entirely non-discriminatory policy $(\theta=0, T=0)$ it is less likely that the majority will vote in favor of immigration. To see this, consider again the critical education level which delimits proponents and opponents of immigration:

$$
h_{c}=\frac{H}{H+L_{Y}+L_{X}(1+\xi)}, \xi=\frac{\left(L_{X} / L\right)\left[\sigma_{Y} s_{H}^{X}-(1+\Delta) \sigma_{X} s_{H}^{Y}\right]}{\eta_{Y} s_{H}^{X} s_{H}^{Y}+\left(L_{X} / L\right)(1+\Delta) \sigma_{X} s_{H}^{Y}},
$$

where $\Delta$ is the sectoral wage differential (see the appendix). The critical education level is greater than the average education level if $\xi<0$ or if

$$
\frac{s_{H}^{X}}{s_{H}^{Y}}<\frac{(1+\Delta) \sigma_{X}}{\sigma_{Y}}
$$

This condition is likely to be satisfied since it seems reasonable to assume that the secondary sector is not much more skill-intensive than the primary sector. ${ }^{14}$

13 When analyzing attitudes towards immigration, we assume for simplicity that no migrants are present at the initial equilibrium.

14 If the elasticities of substitution between skilled and unskilled labor are identical in the two sectors, this condition is satisfied if the secondary sector is as skill-intensive as the primary sector (or less). 
In any case, the critical capital level is higher here than in the extreme "guestworker" case of equation (6) since $\xi<\sigma_{Y} /\left(\eta_{Y} s_{H}^{Y}\right)$. We can therefore conclude that a given increase in low-skill immigration is less likely to be accepted in a non-discriminatory regime than in a guest-worker system.

\subsection{Improved Integration of Immigrants}

In Switzerland, efforts to improve the legal situation of immigrants have often met with resistance. For example, the abolition of the seasonal worker status proposed in 1981 was largely rejected by the Swiss electorate. Such a policy change would have improved the social and economic integration of immigrants and enhanced their chances of finding "good" jobs. In the model, such a qualitative policy change can be captured by reducing $\theta$ or $T$, assuming that the number of immigrants $M$ who live in the country remains constant. As a result of this policy change, the incentive of immigrants to shirk decreases and their chances of finding a job in the primary sector improve.

The consequences for natives are depicted in Figure 1, where this policy change is represented by a shift to the left of the downward-sloping marginal-productivity-of-labor schedule. The wage differential between "good" and "bad" jobs diminishes and native low-skill employment in the primary sector decreases. The natives' attitudes toward the improved integration of immigrants depend on structural parameters. If condition (8) is not satisfied, the proposition will be rejected by all natives. In the more likely case that condition (8) is satisfied, attitudes of natives towards the reform are an increasing function of their education levels and natives whose education level exceeds the following critical level will accept the proposition:

$$
h_{c}=\bar{h}(1+\psi), \psi=\frac{\left(N / L_{Y}-1\right)(1+\Delta) \sigma_{X} s_{H}^{Y}+\sigma_{Y} s_{H}^{X}}{\left(H / L_{Y}+1\right)(1+\Delta) \sigma_{X} s_{H}^{Y}-\sigma_{Y} s_{H}^{X}}>0 .
$$

The critical education level exceeds the average education level if condition (8) is satisfied and if $N>L_{Y}$. The latter condition holds if a guest-worker system was in place before the integration measures are proposed, since only natives work in the primary sector prior to the policy change $\left(N-L_{Y}=N_{X}>0\right)$. Therefore, if the median education level of natives is below the average education level, the improved integration of immigrants will be rejected by a majority of citizens who fear the deterioration of their own economic situation. It should be emphasized that this is an inefficient outcome from the point of view of 
the entire population, since a policy of social integration would increase the number of good jobs at the expense of bad jobs and therefore improve the aggregate welfare of natives and immigrants (MülLER, 2003a). Indeed, were immigrants allowed to vote, it is possible that a majority in favor of the policy change could be found.

In sum, our theoretical framework suggests three main conclusions. First, with segmented labor markets immigration is more likely to be accepted in a "guestworker" system, of the type used in Switzerland in the past, than in a non-discriminatory migration regime. Second, if a "guest-worker" system is in place, an improvement of the legal situation of low-skill immigrants is likely to meet with resistance by natives. As highlighted in the introduction, there are several examples of such behavior in recent Swiss history. Third, attitudes towards the improved integration of low-skill immigrants are likely to be an increasing function of the natives' education level. The last theoretical prediction is addressed for Switzerland from an empirical point of view in the next section.

\section{Empirical Analysis}

In this section, we turn to the empirical evidence on attitudes towards the integration of immigrants in Switzerland. As we will show below, the evidence is consistent with the prediction of the theoretical model that more educated Swiss citizens are more favorable to integration. Although the survey question we analyze seems to refer primarily to the labor market, other theoretical explanations of this empirical pattern cannot be excluded. In particular, individual attitudes towards immigrants depend also on cultural values and beliefs. Hainmueller and Hiscox (2007) suggest that higher levels of education lead to greater tolerance and more openness towards other cultures and argue that the relation between education and attitudes towards immigration has little to do with labor market competition. This problem will be addressed in several ways, as spelled out in Section 3.2 below.

Another question is whether our theoretical model provides an adequate description of the Swiss situation. Two issues stand out. First, our theoretical model neglects the existence of a welfare state and the role of income redistribution. If income redistribution is represented by a linear tax-benefit schedule as in FACCHINI and MAYDA (2009), the improved integration of immigrants in the labor market would increase their incomes and therefore their contribution to tax revenues. With a balanced government budget, the marginal income tax rate could be reduced and high-skill natives (who earn high incomes) would benefit 
even more. ${ }^{15}$ Thus, the positive relationship between the level of education and attitudes towards immigration would be reinforced by income redistribution.

Second, we assume in the theoretical model that immigrants are all of the low-skill type and that voters worry only about the immigrants' access to "good" jobs. Despite the arrival of many high-skill migrants in recent years, we believe that this is a realistic assumption in the Swiss case. On the one hand, the stock of immigrants in Switzerland includes a large share of low-skill immigrants as a result of past policies. On the other hand, highly skilled immigrants are much better integrated in the Swiss labor market than low-skill immigrants. Recent evidence shows that high-skill immigrants tend to earn higher wages than comparably skilled natives whereas the opposite is true for low-skill immigrants (Müller and Ramirez, 2009).

\subsection{Data}

We use data from the Vox surveys which are carried out after each vote at the federal level in Switzerland (on average three votes are held per year), with representative samples of approximately 1000 Swiss citizens for each vote. These surveys take place during the two or three weeks following each vote. Besides questions related to the vote, the survey includes also items on general political opinions and individual values. Our sample includes data from the period June 1993 to November $2008 .{ }^{16}$ We exclude students and individuals in training from the analysis since their reported education level is not representative of their future skill level.

In our empirical analysis, we measure attitudes of Swiss citizens towards the integration of immigrants using the following question: "What do you wish for Switzerland? A Switzerland where foreigners have equal opportunities (chances), or a Switzerland where the Swiss have better chances?"17 Answers are given on a six-point scale ranging from "equal opportunities" to "better chances for the

15 The tax-benefit schedule could also be adjusted by increasing benefits. This seems unlikely and contradicts the empirical findings by FACCHINI and MAYDA (2009) and MÜLLER and TAI (2009).

16 The original data was collected by Gfs Bern. We use the most recent version (5.1) of the standardized VoxIt dataset prepared by the Swiss foundation for research in social sciences (FORS). The votes held on 26 September 1993 and 20 January 1994 are excluded from the analysis because the relevant question was not asked.

17 The original questions in French and German are: «Souhaitez-vous ... une Suisse où les étrangères et les étrangers ont les mêmes chances, ou une Suisse où les Suissesses et les Suisses ont de meilleures chances?», „Möchten sie ... eine Schweiz mit gleichen Chancen für alle oder eine Schweiz ohne Chancengleichheit?" 
Swiss". Although this question does not explicitly refer to the labor market, we assume that most respondents relate "equal opportunities" to the absence of discrimination in the labor market, and therefore to the probability of obtaining a good job. The notion of "equal chances" might also bring to mind the absence of discrimination in education; but in our case this does not seem a central issue since it concerns only the second generation of immigrants.

The main explanatory variable in our analysis is the level of education which is coded as a categorical variable in the survey. Alternatively, we use a quantitative variable "years of education" which is obtained by attributing a certain number of years of education to each category, following FLÜCKIGER and ZARIN NejADAN (2000). We account for geographic differences in cultural norms and political attitudes by including dummy variables for the 25 cantons and for the three main linguistic regions of the country (the German-speaking part is the reference). The influence of the business cycle and of other time-varying factors on attitudes is captured by year dummies. In the survey, political beliefs of citizens are measured by a variable based on the individual's self-assessment of his political position on a scale between 0 (left) and 10 (right). We classify those who pick a number between 0 and 4 as being on the "left" and those who indicate numbers between 6 and 10 as belonging to the "right". Almost 45 percent of the population chooses to represent their position at the center of the scale.

It would be useful to have a variable measuring an individual's work income. Unfortunately, the survey provides only a categorical variable indicating household income. There are only five income categories and the boundaries between categories are not indexed over time. ${ }^{18}$ We also define a "continuous" household income variable, using the mid-points of the income intervals (and deflating these values by the Swiss consumer price index). Because of its limitations, we will use this variable as a robustness check.

\subsection{Empirical Results}

Answers by Swiss citizens to the question about equal opportunities for foreigners confirm our casual interpretation of past federal votes on related subjects: in our sample there is no clear majority in favor of measures that would enhance the foreigners' chances in the labor market. Almost one in four Swiss citizens is in

18 The five income categories are: (1) less than $3000 \mathrm{CHF}$ per month; (2) between $3000 \mathrm{CHF}$ and $5000 \mathrm{CHF}$ per month; (3) between $5000 \mathrm{CHF}$ and $7000 \mathrm{CHF}$ per month; (4) between $7000 \mathrm{CHF}$ and $9000 \mathrm{CHF}$ per month; (5) more than $9000 \mathrm{CHF}$ per month. 
Table 1: Descriptive Statistics

\begin{tabular}{lcc}
\hline & Mean & Std. Dev. \\
\hline Dependent variables: & & \\
\hline Attitudes (ordinal) & & \\
1 - better chances for the Swiss & 0.229 & \\
2 & 0.123 \\
3 & 0.126 \\
4 & 0.173 \\
5 & 0.104 \\
6- equal opportunities & 0.244 \\
Attitudes (binary) & 0.521 \\
\hline Explanatory variables & \\
\hline Years of education & 12.73 \\
Age & 49.00 \\
French & 0.23 \\
Italian & 0.06 \\
Female & 0.51 \\
Left & 0.29 \\
Right & 0.27 \\
Household income & \\
-Up to 3000 CHF & 0.130 \\
-From 3001 to 5000 CHF & 0.291 \\
-From 5001 to 7000 CHF & 0.274 \\
-From 7001 to 9000 CHF & 0.162 \\
-Above 9000 CHF & 0.143 \\
\hline
\end{tabular}

favor of "equal opportunities for foreigners", whereas another fourth supports the idea that the Swiss should have better chances; the remaining half of the sample chooses an intermediate opinion. Only a slight majority (52 percent) provides answers in the "positive" half of the scale (i.e. closer to "equal opportunities"). ${ }^{19}$

To sort out the role of education in attitudes towards the integration of immigrants in the labor market, we run regressions with different measures of

19 Interestingly, when the same citizens are asked the more general question whether they are in favor of a Switzerland "where there is equality of opportunities" (without any reference to a category of population), 69 percent answer in the affirmative. A very large majority (93 percent) provides answers in the "positive" half of the answer scale. 
education. As the answer scale is ordinal, we use an ordered probit model; standard errors are adjusted for clustering by vote. First, we proceed by analogy to a Mincer earnings equation and assume that attitudes are a linear function of years of education. Results are reported in column (1) of Table 2. The coefficient of education years is highly significant from a statistical point of view. How much of this effect is due to the fact that education reflects labor-market skills rather than cultural values?

To address this question we follow Scheve and Slaughter (2001) and distinguish individuals who are in the labor force (employed or unemployed) from those who are not. The influence of education on attitudes should be stronger for the former than for the latter if the labor-market mechanism is important. The results of column (2) give some support for the labor market mechanism since the marginal influence of education is significantly higher for individuals in the labor force. However, the difference between the two groups is not very large in quantitative terms (the coefficient is about 30 percent higher for those in the labor force) which suggests that non-economic factors might play a role in the determination of attitudes.

An alternative way of looking at the same question consists in exploiting the dual nature of the Swiss education system and to distinguish individuals who followed a vocational education from those who chose the academic path. The return to the two types of education should be different if HainmuelLER and Hiscox's (2007) conjecture that college education makes individuals become more tolerant to other cultures were correct. The results in column (3) of Table 2 indicate that there is a significant difference between the two types of education but do not lend full support to Hainmueller and Hiscox's (2007) conjecture since it is for lower education levels that the two types differ the most (and the return to vocational education seems to be higher than to academic education). Specification (4) which uses dummy variables for different education levels, confirms this result: those who finish an apprenticeship are significantly less favorable to immigrants' integration than those who have a high-school degree. The difference is smaller between the two types of college degrees.

In Switzerland, the debate on migration policy became increasingly polarized along the right-left axis during the 1990s. Therefore, the political dimension of attitudes towards immigrants' integration should be taken into account in our analysis. In specifications (5) and (6) of Table 2 we test whether our results are robust to the introduction of the variables indicating a "left" or "right" political orientation. Indeed, these variables turn out to be important determinants of attitudes. Moreover, the influence of education on attitudes remains highly 


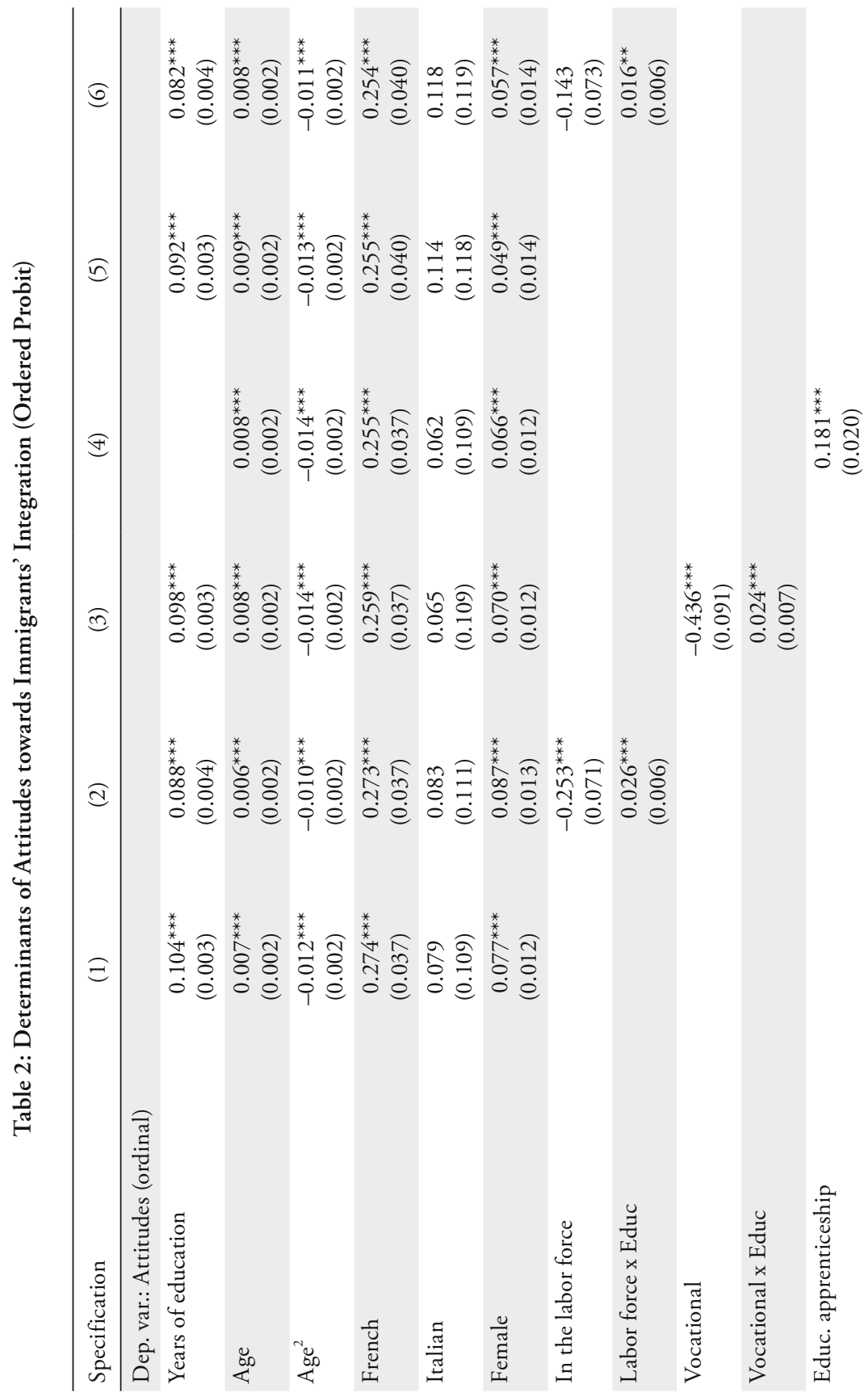




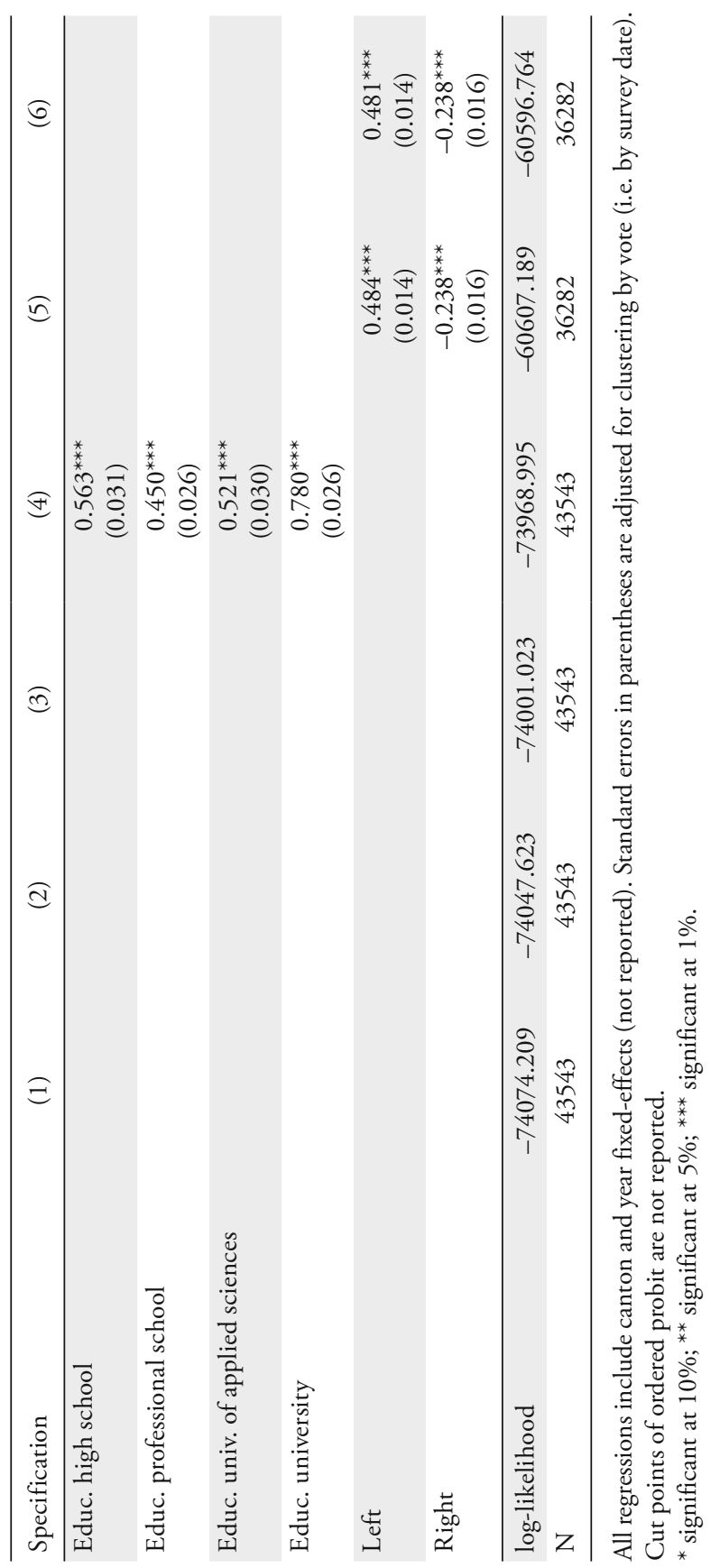


significant in both specifications and it is still significantly greater for individuals in the labor force (specification (6)). ${ }^{20}$

As a robustness check, we reestimate the model using information on household income. To ensure comparability between different specifications of the model, we recode the dependent variable as a binary variable (distinguishing the two "halves" of the answer scale) and estimate the model by simple probit. Marginal effects are reported in Table 3. If we include household income, either as a continuous variable in specification (8) or as a categorical variable in specification (10), the regression results do not change our main conclusions but shed some more light on the link between individual skill and attitudes. First, the marginal effect of education on attitudes decreases only slightly when the household income variable is introduced. This is probably due to the fact that education remains a more reliable indicator of an individual's skill level than the income variable which is measured with error and includes the income of other household members. Second, household income is strongly significant from a statistical point of view, although its effect on attitudes is economically not very important (increasing income from the lowest to the highest category increases the probability of being in favor of immigrants' integration only by 6 percentage points). Possible explanations of this result are that household income includes some unmeasured skill of the individual or that individuals care for their partners' situation when considering their attitudes towards immigrants.

The marginal effects reported in Table 3 enable us to conclude by appraising the economic significance of our main results. According to specification (7), the effect of education on attitudes is strong: one additional year of education increases the probability of being in favor of immigrants' integration by 4.6 percentage points. Specification (9) confirms the result that academic education leads to more open attitudes towards immigrants' integration than vocational education and training. By contrast to Hiscox and Hainmueller's (2007) conjecture, the difference between the academic and the vocational path appears already at lower education levels: those who have graduated from high school level are much more likely (by 14 percentage points) to favor immigrants' integration than those who have finished an apprenticeship.

20 One should be careful not to compare the coefficients of specifications (5) and (6) with the other results in Table 1. First, the sample is markedly smaller in the former case because a substantial proportion of individuals do not indicate their political orientation. Second, as the cut points of the ordered probit differ from one specification to the other, the marginal effects of variables might be different even if the regression coefficients are identical. 
Table 3: The Role of Education and Income in Attitudes (Probit, Marginal Effects)

\begin{tabular}{|c|c|c|c|c|}
\hline Specification & (7) & (8) & (9) & (10) \\
\hline \multicolumn{5}{|l|}{ Dep. var.: Attitudes (binary) } \\
\hline Years of education & $\begin{array}{l}0.046^{* * *} \\
(0.002)\end{array}$ & $\begin{array}{l}0.043^{* * *} \\
(0.002)\end{array}$ & & \\
\hline Age & $\begin{array}{l}0.004^{* * *} \\
(0.001)\end{array}$ & $\begin{array}{l}0.003^{* *} \\
(0.001)\end{array}$ & $\begin{array}{l}0.005^{* * *} \\
(0.001)\end{array}$ & $\begin{array}{l}0.003^{* *} \\
(0.001)\end{array}$ \\
\hline $\mathrm{Age}^{2}$ & $\begin{array}{l}-0.006^{* * *} \\
(0.001)\end{array}$ & $\begin{array}{l}-0.005^{* * *} \\
(0.001)\end{array}$ & $\begin{array}{l}-0.007^{* * *} \\
(0.001)\end{array}$ & $\begin{array}{l}-0.005^{* * *} \\
(0.001)\end{array}$ \\
\hline French & $\begin{array}{l}0.095^{* * *} \\
(0.018)\end{array}$ & $\begin{array}{l}0.097^{* * *} \\
(0.018)\end{array}$ & $\begin{array}{l}0.088^{* * *} \\
(0.018)\end{array}$ & $\begin{array}{l}0.090^{* * *} \\
(0.018)\end{array}$ \\
\hline Italian & $\begin{array}{l}-0.005 \\
(0.061)\end{array}$ & $\begin{array}{l}-0.002 \\
(0.061)\end{array}$ & $\begin{array}{l}-0.011 \\
(0.062)\end{array}$ & $\begin{array}{l}-0.008 \\
(0.061)\end{array}$ \\
\hline Female & $\begin{array}{l}0.036^{* * *} \\
(0.007)\end{array}$ & $\begin{array}{l}0.038^{* * *} \\
(0.007)\end{array}$ & $\begin{array}{l}0.031^{* * *} \\
(0.007)\end{array}$ & $\begin{array}{l}0.034^{* * *} \\
(0.007)\end{array}$ \\
\hline Income & & $\begin{array}{l}0.089^{* * *} \\
(0.016)\end{array}$ & & \\
\hline Educ. apprenticeship & & & $\begin{array}{l}0.083^{* * *} \\
(0.011)\end{array}$ & $\begin{array}{l}0.076^{* * *} \\
(0.011)\end{array}$ \\
\hline Educ. high school & & & $\begin{array}{l}0.223^{* * *} \\
(0.013)\end{array}$ & $\begin{array}{l}0.212^{* * *} \\
(0.013)\end{array}$ \\
\hline Educ. professional school & & & $\begin{array}{l}0.184^{* * *} \\
(0.012)\end{array}$ & $\begin{array}{l}0.174^{* * *} \\
(0.012)\end{array}$ \\
\hline Educ. univ. of applied sciences & & & $\begin{array}{l}0.218^{* * *} \\
(0.012)\end{array}$ & $\begin{array}{l}0.203^{* * *} \\
(0.012)\end{array}$ \\
\hline Educ. university & & & $\begin{array}{l}0.311^{* * *} \\
(0.011)\end{array}$ & $\begin{array}{l}0.296^{* * *} \\
(0.012)\end{array}$ \\
\hline $\begin{array}{l}\text { Income from } \\
3001 \text { to } 5000 \mathrm{CHF}\end{array}$ & & & & $\begin{array}{c}0.015 \\
(0.009)\end{array}$ \\
\hline $\begin{array}{l}\text { Income from } \\
5001 \text { to } 7000 \mathrm{CHF}\end{array}$ & & & & $\begin{array}{l}0.030^{* *} \\
(0.010)\end{array}$ \\
\hline $\begin{array}{l}\text { Income from } \\
7001 \text { to } 9000 \mathrm{CHF}\end{array}$ & & & & $\begin{array}{l}0.047^{* * *} \\
(0.012)\end{array}$ \\
\hline $\begin{array}{l}\text { Income above } \\
9000 \mathrm{CHF}\end{array}$ & & & & $\begin{array}{l}0.061^{* * *} \\
(0.014)\end{array}$ \\
\hline log-likelihood & -23822.647 & -23800.742 & -23760.697 & -23741.810 \\
\hline $\mathrm{N}$ & 36160 & 36160 & 36160 & 36160 \\
\hline
\end{tabular}

All regressions include canton and year fixed-effects (not reported). Standard errors in parentheses are adjusted for clustering by vote (i.e. by survey date).

${ }^{*}$ significant at $10 \%$; ${ }^{* *}$ significant at $5 \%$; ${ }^{* * *}$ significant at $1 \%$. 
Finally, cultural differences in attitudes are very important: individuals living in the French-speaking part of Switzerland are by far (by almost 10 percentage points) more inclined to extend equal opportunities to immigrants than in the other regions of Switzerland. It should be emphasized that this effect is identified using within-canton differences in attitudes since our estimations use fixed effects at the canton level. Finally, groups that are more open towards the integration of immigrants are women and the young (around the age of 30, attitudes are the most favorable).

\section{Conclusion}

We develop a political-economy model explaining why natives tend to oppose the integration of immigrants in the labor market if the country had adopted a guest-worker system in the past. The model, which is based on segmented labor markets, accounts also for the fact that a guest-worker system is chosen in the first place: immigration is more likely to be accepted in a guest-worker system than in a non-discriminatory immigration regime. Furthermore, natives' attitudes towards integration are an increasing function of their education level, according to this theoretical framework.

Applying Swiss data from Vox surveys over the period 1993 to 2008, we estimate the relationship between individual education and natives' attitudes towards immigrants' integration. Switzerland provides an interesting context for this empirical analysis because it had historically implemented guest-worker programs and had also experienced resistance by natives to the integration of immigrants.

Following the methodology of Scheve and Slaughter (2001), we find that economic and non-economic factors both play a significant role in the positive relationship between natives' education and attitudes towards the integration of immigrants. For natives who are in the labor market, the marginal impact of education on attitudes is stronger than for those who are not, indicating that labormarket competition seems to play a significant role in attitudes. On the other hand, for a given number of years of education, natives that followed an academic education are more favorable to the integration of immigrants than those who undertook vocational education and training. This latter result tends to support the view that academic education leads to more open attitudes to ethnic diversity, a result which complements HainmuelLer and Hiscox's (2007) argument that individuals with a college or university degree are more tolerant to other cultures. 


\section{Appendix: The Model}

In this appendix, the main results of the efficiency-wage model presented in Section 2 are derived in detail. Workers are assumed to maximize expected utility over their infinite life horizon, using discount rate $r$. Consider first the situation of low-skill natives. The problem of a worker in the primary sector who has to decide whether to shirk or not, can be analyzed by relating the utility levels that he can attain in the two cases. Let $U_{Y}^{s}\left(U_{Y}^{n}\right)$ denote the expected present value of utility of a shirking (non-shirking) worker holding a primary-sector job. Let $U_{X}$ denote the expected utility of a secondary-sector job. To relate these situations, the asset-equation approach introduced by SHAPIRO and STIGLITZ (1984) is followed. A worker who shirks faces a probability $b$ per unit time of being discovered and fired. Moreover, there is an exogenous probability $q$ per unit time for each primary-sector job to end; in that case the worker takes up a job in the secondary sector. If a worker has a job in the primary sector, he receives wage $w_{L}^{Y}$. He earns the following return, according to whether he shirks or not:

$$
\begin{gathered}
r U_{Y}^{n}=w_{L}^{Y}-e-q\left(U_{Y}^{n}-U_{X}\right), \\
r U_{Y}^{s}=w_{L}^{Y}-(q+b)\left(U_{Y}^{s}-U_{X}\right) .
\end{gathered}
$$

A worker in the primary-sector does not shirk if $U_{Y}^{n} \geq U_{Y}^{s}$. At equilibrium, there is no shirking and this condition holds with equality since there is no reason for a primary-sector firm to pay a higher wage. Using equations (A1) and (A2), the no-shirking condition can be rewritten as follows:

$$
b\left(U_{Y}^{n}-U_{X}\right)=e .
$$

The return to a job in the secondary sector is equal to:

$$
r U_{X}=w_{L}^{X}-e+\alpha\left(U_{Y}-U_{X}\right) .
$$

In a steady-state equilibrium, the probability $\alpha$ of moving from a secondarysector job to a primary-sector job is determined as follows. The flow out of the primary sector is $q N_{Y}$, where $N_{Y}$ is native employment in the primary sector. The flow into the primary sector is $\alpha\left(N-N_{Y}\right)$, where $N$ is total native employment. At equilibrium, these two must be equal. Thus, for natives $\alpha$ is given by $q N_{Y} /\left(N-N_{Y}\right)$ and, using (A1) and (A4), the natives' no-shirking condition (A3) can be rewritten as equation (3) in the main text. 
If immigrants have the same labor rights as natives only after $T$ years, the number of immigrants eligible for primary-sector jobs is given by $M^{*}=M \exp (-$ $\theta T$ ), where $\theta$ is the probability of return migration. The no-shirking condition of immigrants is given by:

$$
w_{L}^{Y}-w_{L}^{X}=\frac{e}{b}\left(r+\frac{(q+\theta) M^{*}}{M^{*}-M_{Y}}\right)
$$

Combining the NSC of natives and migrants yields equation (4).

Now turn to the consequences of "infinitesimal" immigration under different migration policies. Primary-sector employment by migrants can be parameterized by $M_{Y}=\lambda M$, where $\lambda=N_{Y} / N$ designates the non-discriminatory policy and $\lambda=0$ the extreme guest-worker scheme. Denote total primary employment by $L_{Y}=N_{Y}+M_{Y}$ and total secondary employment by

$$
L_{X}=N_{X}+M_{X}=N-N_{Y}+M-M_{Y} .
$$

Assuming an infinitesimal variation $d M$ in immigration stock and differentiating the marginal-product-of-labor conditions for low-skill labor,

$$
w_{L}^{i}=f_{L}^{i}\left(H_{i}, L_{i}\right)(i=X, Y),
$$

the following variation in the wage differential is obtained:

$$
d w_{L}^{Y}-d w_{L}^{X}=f_{L L}^{Y} d L_{Y}-f_{L L}^{X} d L_{X}
$$

On the other hand, differentiating the NSC (3):

$$
d w_{L}^{Y}-d w_{L}^{X}=A d N_{Y}, A=\frac{\left(\frac{e q}{b}\right) N}{\left(N-N_{Y}\right)^{2}} .
$$

Since $d L_{X}=(1-\lambda) d M-d N_{Y}$ and $d L_{Y}=d N_{Y}+\lambda d M$, it is clear that

$$
(1-\lambda) d L_{Y}-\lambda d L_{X}=d N_{Y} .
$$


This allows to combine equations (A6) and (A7) to yield:

$$
\frac{d L_{X}}{d L_{Y}}=\frac{f_{L L}^{Y}-(1-\lambda) A}{f_{L L}^{X}-\lambda A} .
$$

Now turn to the variation in expected life-time utility of natives. Differentiating (A1) and (A3) yields $d U_{X}=d U_{Y}$ and the change in natives' expected utility becomes

$$
\begin{aligned}
d U_{i}^{e} & =h_{i} d U_{H}+\left(1-h_{i}\right) d U_{X} \\
& =\frac{1}{r}\left[h_{i}\left(\pi_{X} d w_{H}^{X}+\left(1-\pi_{X}\right) d w_{H}^{Y}\right)+\left(1-h_{i}\right) d w_{L}^{Y}\right] .
\end{aligned}
$$

For the subsequent calculations, we use

$$
d w_{H}^{i}=f_{H L}^{i} d L_{i}, i=X, Y
$$

and, assuming constant returns to scale in production,

$$
d w_{L}^{Y}=f_{L L}^{Y} d L_{Y}=-\left(\frac{H_{Y}}{L_{Y}}\right) f_{H L}^{Y} d L_{Y} .
$$

A native with education level $h_{i}$ accepts immigration if his utility increases with immigration. As immigration implies $d L_{Y}>0$, and assuming that there are no migrants present at the initial equilibrium $(M=0)$ this condition is equivalent to:

$$
h_{i}>\frac{H}{H+L_{Y}+L_{X}(1+\xi)}, \xi=\frac{(1-\lambda) \sigma_{Y} s_{H}^{X}-\lambda \ell(1+\Delta) \sigma_{X} s_{H}^{Y}}{\eta_{Y} s_{H}^{X} s_{H}^{Y}+\lambda \ell(1+\Delta) \sigma_{X} s_{H}^{Y}},
$$

where $\ell=L_{X} / L_{Y}, \Delta=\left(w_{L}^{Y} / w_{L}^{X}\right)-1$ is the wage differential, $\sigma_{i}=\left(f_{H}^{i} f_{L}^{i}\right) /\left(f^{i} f_{H L}^{i}\right)$ is the elasticity of substitution between low-skill and high-skill labor in sector $i$, and $\eta_{Y}=w_{Y} /\left(A N_{Y}\right)$ the elasticity of primary-sector employment with respect to wage on the NSC. Equations (6) and (7) in the text are special cases of (A10), with $\lambda=0$ and $\lambda=N_{Y} / N=L_{Y} / L$ respectively.

Consider now a policy of improved economic and social integration of immigrants, which can be captured in the model by a decrease in parameters $\theta$ and/ or $T$. Assuming a constant stock of immigrants and differentiating (4) yields 


$$
\frac{d M_{Y}}{M}=d I+a\left(\frac{d N_{Y}}{N}\right), \text { where } a=e^{-\theta T}\left(1+\frac{\theta}{q}\right)
$$

and $d I$ denotes a policy change towards improved integration of migrants ( $d I$ is equal to a weighted sum of $(-d \theta)$ and $(-d T))$. Then:

$$
d L_{Y}=d N_{Y}+d M_{Y}=(1+a m) d N_{Y}+M d I,
$$

where $m=M / N$. As there is no new immigration, $d L_{X}=-d L_{Y}$ and combining (A6) and (A7) results in: $d N_{Y}=d L_{Y}\left(f_{L L}^{Y}+f_{L L}^{X}\right) / A$. Combining the latter equation with (A11) establishes that $d L_{Y} / d I>0$ and $d N_{Y} / d I<0$. As total employment is unchanged, we have:

$$
d U_{i}^{e}=\frac{1}{r}\left(f_{L L}^{Y}-\frac{h_{i}}{H}\left(\left(H+L_{Y}\right) f_{L L}^{Y}-L_{X} f_{L L}^{X}\right)\right) d L_{Y} .
$$

If $\left(H+L_{Y}\right) f_{L L}^{Y}-L_{X} f_{L L}^{X}>0$, or equivalently

$$
\frac{s_{H}^{X}}{s_{H}^{Y}}>\left(\frac{H}{L_{Y}+1}\right)(1+\Delta)\left(\frac{\sigma_{X}}{\sigma_{Y}}\right),
$$

$d U / d I$ is negative for all $h_{i} \geq 0$. In the opposite case (which is implied by condition (8) in the text), a native with education level $h_{i}$ is in favor of improved integration of immigrants if

$$
h_{i}>\frac{H f_{L L}^{Y}}{\left(H+L_{Y}\right) f_{L L}^{Y}-L_{X} f_{L L}^{X}} .
$$

This condition is equivalent to the condition $h_{i}>h_{c}$, with $h_{c}$ defined by equation (9) in the text. 


\section{References}

Bauer, Thomas K., Magnus Lofstrom, and Klaus F. Zimmermann (2000), "Immigration Policy, Assimilation of Immigrants and Natives' Sentiments towards Immigrants: Evidence from 12 OECD-Countries", IZA Discussion Paper No. 187.

Bulow, Jeremy I., and Lawrence H. Summers (1986), "A Theory of Dual Labor Markets with Application to Industrial Policy, Discrimination, and Keynesian Unemployment", Journal of Labor Economics, 4 (3), pp.376-414.

Castles, Stephen (1986), "The Guest-Worker in Western Europe: An Obituary”, International Migration Review, 20 (4), 761-778.

Dustmann, Christian (1993), "Earnings Adjustment of Temporary Migrants", Journal of Population Economics, 6, pp. 153-168.

Dustmann, Christian, and Ian P. Preston (2007), "Racial and Economic Factors in Attitudes to Immigration", The B. E. Journal of Economic Analysis \& Policy, 7 (1), Advances, Article 62.

Facchini, Giovanni, and Anna Maria Mayda (2008), "From Individual Attitudes towards Migrants to Migration Policy Outcomes: Theory and Evidence", Economic Policy, 56, pp. 651-713.

Facchini, Giovanni, and Anna Maria Mayda (2009), "Individual Attitudes towards Immigrants: Welfare-State Determinants across Countries", Review of Economics and Statistics, 91 (2), pp.295-314.

Fibbi, Rosita, Mathias Lerch, and Philippe Wanner (2006), "Unemployment and Discrimination against Youth of Immigrant Origin in Switzerland: When the Name Makes the Difference", Journal of International Migration and Integration, 7 (3), pp.351-366.

Goldberg, Andreas, Dora Mourinho and Ursula Kulke (1996), "Labour Market Discrimination against Foreign Workers in Germany", International Migration Papers 7, International Labour Office, Geneva.

Hainmueller, Jens, and Michael J. Hiscox (2007), "Educated Preferences: Explaining Attitudes Toward Immigration in Europe", International Organization, 61, pp.399-442.

Hanson, Gordon H., Kenneth F. Scheve and Matthew J. Slaughter (2007), "Local Public Finance and Individual Preferences over Globalization Strategies", Economics and Politics, 19, pp. 1-33.

Flückiger, Yves, and Milad Zarin Nejadan (2000), «Intégration de la population étrangère en Suisse: aspects économiques», rapport au Fonds National Suisse, mimeo. 
Goldberg, Andreas, Dora Mourinho, and Ursula Kulke (2010), "Ethnic Discrimination in Germany's Labour Market: A Field Experiment”, IZA Discussion Paper No. 4741.

Mayda, Anna Maria (2006), "Who is against Immigration? A Cross-Country Investigation of Individual Attitudes toward Immigrants", Review of Economics and Statistics, 88 (3), pp. 510-530.

Mayer, Kurt B. (1965), "Postwar Migration from Italy to Switzerland", International Migration Digest, 1 (2), pp.5-13.

de Melo, Jaime, Florence Miguet, and Tobias Müller (2002), “The Political Economy of EU Enlargement: Lessons from Switzerland”, CEPR Discussion Paper No 3449.

Müller, Tobias (2003a), "Migration Policy in a Small Open Economy with a Dual Labor Market", Review of International Economics, 11 (1), pp. 130-143. Müller, Tobias (2003b), "Migration, Unemployment and Discrimination", European Economic Review, 47, pp.409-427.

Müller, Tobias, and José Ramirez (2009), "Wage Inequality and Segregation between Native and Immigrant Workers in Switzerland: Evidence Using Matched Employee-Employer Data”, Research on Economic Inequality, 17, pp. 205-243.

Müller, Tobias, and Silvio H. T. Tai (2009), "Individual Attitudes towards Migration: A Reexamination of the Evidence", mimeo University of Geneva. Piguet, Etienne, and Hans Mahnig (2000), "Quotas d'immigration: L'expérience de la Suisse», Cahiers de migrations internationales, 37, International Labour Office, Geneva.

OECD (2008), International Migration Outlook (SOPEMI), OECD, Paris.

O’Rourke, Kevin H., and Richard Sinnott (2006), "The Determinants of Individual Attitudes Towards Immigration", European Journal of Political Economy, 22: pp. 838-861.

Scheve, Kenneth F., and Matthew. J. Slaughter (2001), "Labor Market Competition And Individual Preferences Over Immigration Policy", Review of Economics and Statistics, 83 (1): pp. 133-145.

Shapiro, Carl, and Joseph E. Stiglitz (1984), "Equilibrium Unemployment as a Worker Discipline Device”, American Economic Review, 74 (3), pp.433-444. 


\section{SUMMARY}

First, we spell out a political-economy model, based on segmented labor markets, which explains why a guest-worker system is preferred to a non-discriminatory immigration regime and why measures to improve the integration of low-skill immigrants tend to be opposed subsequently. The model also predicts that attitudes towards the integration of immigrants are positively related to education. Second, we examine the empirical evidence on attitudes towards the integration of immigrants. Our findings from Swiss data are consistent with the prediction of the theoretical model. Both economic and non-economic factors seem to matter in the positive relationship between attitudes and education. 